\title{
Effect of Statins on Mortality in Heart Failure With Preserved Ejection Fraction Without Coronary Artery Disease - Report From the JASPER Study -
}

\author{
Kyohei Marume, MD, PhD; Seiji Takashio, MD, PhD; Toshiyuki Nagai, MD, PhD; \\ Kenichi Tsujita, MD, PhD; Yoshihiko Saito, MD, PhD; \\ Tsutomu Yoshikawa, MD, PhD; Toshihisa Anzai, MD, PhD
}

\begin{abstract}
Background: Statins might be associated with improved survival in patients with heart failure with preserved ejection fraction (HFpEF). The effect of statins in HFpEF without coronary artery disease (CAD), however, remains unclear.

Methods and Results: From the JASPER registry, a multicenter, observational, prospective cohort with Japanese patients aged $\geq 20$ years requiring hospitalization with acute $\mathrm{HF}$ and $\mathrm{LVEF} \geq 50 \%, 414$ patients without $\mathrm{CAD}$ were selected for outcome analysis. Based on prescription of statins at admission, we divided patients into the statin group $(n=81)$ or no statin group $(n=333)$. We followed them for 25 months. The association between statin use and primary (all-cause mortality) and secondary (non-cardiac death, cardiac death, or rehospitalization for HF) endpoints was assessed in the entire cohort and in a propensity score-matched cohort. In the propensity score-matched cohort, 3-year mortality was lower in the statin group (HR, $0.21 ; 95 \% \mathrm{Cl}: 0.06-0.72 ; \mathrm{P}=0.014)$. The statin group had a significantly lower incidence of non-cardiac death $(P=0.028)$ and rehospitalization for $H F(P<0.001)$, but not cardiac death $(\mathrm{P}=0.593)$. The beneficial effect of statins on mortality did not have any significant interaction with cholesterol level or HF severity.
\end{abstract}

Conclusions: Statin use has a beneficial effect on mortality in HFpEF without CAD. The present findings should be tested in an adequately powered randomized clinical trial.

Key Words: All-cause death; Heart failure with preserved ejection fraction; Non-ischemic heart failure; Statin

$\mathbf{N}$ early half of community-based patients with heart failure (HF) have preserved left ventricular ejection fraction (LVEF), and the number of patients with $\mathrm{HF}$ with preserved EF (HFpEF) has been rapidly increasing worldwide. ${ }^{1-3}$ Moreover, patients with HFpEF have high mortality and morbidity, ${ }^{3-5}$ making it a major health problem. Unlike in HF with reduced ejection fraction, however, previous randomized clinical trials with cardioprotective drugs, including angiotensin-converting enzyme inhibitors (ACEI), ${ }^{6}$ angiotensin II receptor blockers (ARB), ${ }^{7,8}$ aldosterone antagonists, ${ }^{9}$ and $\beta$-blockers, ${ }^{10}$ showed that they are not effective with regard to mortality in HFpEF. Therefore, establishing how to manage HFpEF is currently an urgent matter.

The effect of hydroxymethylglutaryl-coenzyme A reductase inhibitors (statins) on clinical outcomes in HFpEF has

\begin{abstract}
Editorial p277
been reported in prospective and retrospective observational studies. ${ }^{11-18}$ These previous studies included patients with and without coronary artery disease (CAD). Although the beneficial effects of statins in patients with CAD has been established, ${ }^{19-23}$ the effects of statins in HF patients without CAD remains unknown.

In addition to lipid-lowering effects, statins have pleiotropic effects, ${ }^{24-31}$ such as prevention of LV fibrosis and hypertrophy, improvement of endothelial dysfunction and arterial stiffness, and an anti-inflammatory effect, all of which can contribute to the pathophysiology of HFpEF without CAD. ${ }^{32,33}$ No study, however, has assessed the effects of statins in HFpEF patients without CAD in detail.
\end{abstract}

Received May 31, 2018; revised manuscript received August 22, 2018; accepted October 2, 2018; J-STAGE Advance Publication released online November 9, 2018 Time for primary review: 25 days

Department of Cardiovascular Medicine, Graduate School of Medical Sciences, Kumamoto University, Kumamoto (K.M., S.T., K.T.); Department of Cardiovascular Medicine, Hokkaido University Graduate School of Medicine, Sapporo (T.N., T.A.); Department of Cardiovascular Medicine, National Cerebral and Cardiovascular Center, Suita (T.N., T.A.); First Department of Internal Medicine, Nara Medical University, Kashihara (Y.S.); and Department of Cardiology, Sakakibara Heart Institute, Tokyo (T.Y.), Japan

Mailing address: Seiji Takashio, MD, PhD, Department of Cardiovascular Medicine, Graduate School of Medical Sciences, Kumamoto University, 1-1-1 Honjyo, Kumamoto 860-8556, Japan. E-mail: s-takash@kumamoto-u.ac.jp

ISSN-1346-9843 All rights are reserved to the Japanese Circulation Society. For permissions, please e-mail: cj@j-circ.or.jp 


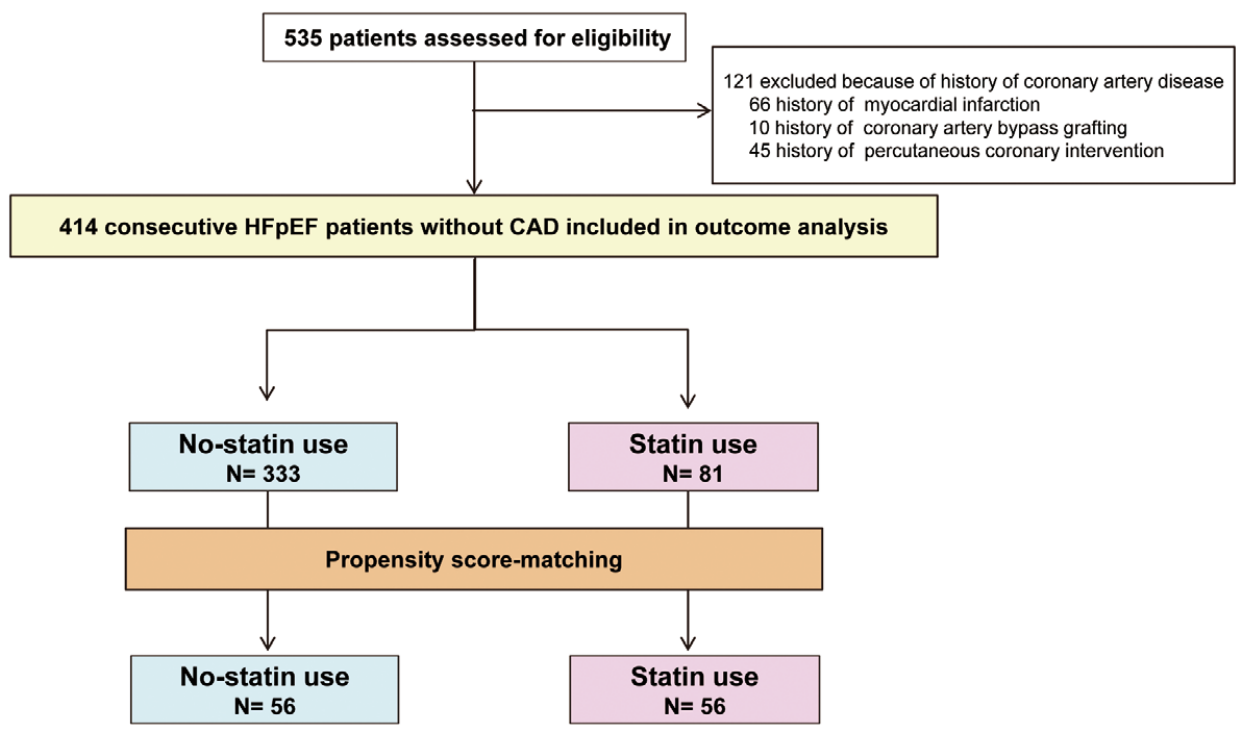

Figure 1. Flow chart of patient selection according to statin use. CAD, coronary artery disease; HFpEF, heart failure with preserved ejection fraction.

We conducted this study to elucidate the efficacy of statins with regard to mortality in $\mathrm{HFpEF}$ patients without CAD.

\section{Methods}

\section{Data Sources}

The Japanese heart failure Syndrome with Preserved Ejection fRaction (JASPER) registry is a multicenter, observational, prospective cohort of 535 patients aged $\geq 20$ years who required hospitalization between July 2012 and March 2015 with a diagnosis of acute HF according to the Framingham criteria, ${ }^{34}$ by at least 2 experienced cardiologists. Patients in the registry had preserved LV systolic function, defined as LVEF $\geq 50 \%$ with the modified Simpson method, or LV fractional shortening $\geq 25 \%$ on echocardiography. Echocardiography was performed using commercially available ultrasound equipment. The median duration between echocardiography and admission was 0 days (IQR, $0-1$ days). Patients with acute coronary syndrome (ACS), receiving hemodialysis, or with a history of heart transplantation were excluded. ${ }^{35}$

Patient demographic data including comorbidity, clinical signs, laboratory and echocardiographic data, in-hospital treatment including oral and i.v. medication, and length of hospital stay, were obtained. Follow-up was performed at hospital discharge and at 12 and 24 months after discharge through direct contact with patients or their physicians in the hospital or outpatient clinic setting, or via patient interview by telephone and mail by dedicated coordinators and investigators. If patients were deceased, their family members were contacted. In this study, because patient information was anonymized and de-identified prior to analysis, written informed consent was not obtained from each patient. We publicized the study, however, by posting an easy-to-understand summary of the protocol on the website of the National Cerebral and Cardiovascular Center. This notice clearly informed patients of their right to refuse enrollment. This study, including the procedure for enrollment, conformed to the principles of the Declaration of Helsinki and has been approved by the institutional review board of each participating site. It was registered under the Japanese UMIN Clinical Trials Registration (UMIN000010601).

\section{Subjects}

Absence of CAD was defined as no history of CAD at the beginning of the study. ${ }^{36} \mathrm{~A}$ history of CAD included a history of myocardial infarction (MI) or coronary revascularization (percutaneous coronary intervention $[\mathrm{PCI}]$ or coronary artery bypass grafting [CABG]). After excluding patients with a history of $C A D$, the remaining patients were included in the outcome analysis.

\section{Follow-up and Endpoints}

The primary endpoint of the present study was all-cause death. The principal secondary endpoints were non-cardiac death and cardiac death, which included sudden cardiac death (SCD) and HF death. Rehospitalization for HF was an additional secondary endpoint. The duration of the follow-up period was calculated from the day of admission until an endpoint occurred or the last patient contact. SCD was defined as unexpected death either $\leq 1 \mathrm{~h}$ after cardiac symptoms in the absence of progressive cardiac deterioration, during sleep, or $\leq 24 \mathrm{~h}$ after last being seen alive. ${ }^{37}$ HF death was defined as death associated with unstable, progressive deterioration of pump function despite active therapy. Rehospitalization for HF was defined as unexpected hospitalization for HF.

\section{Statistical Analysis}

All continuous variables are presented as mean \pm SD . Unpaired t-test was used to compare groups. Non-normally distributed variables are presented as median (IQR). Non-continuous and categorical variables are presented as 
Table 1. Baseline Clinical Characteristics vs. Statin Use and Propensity Score Matching

Entire cohort $(n=414)$

\begin{tabular}{|c|c|c|c|c|c|c|}
\hline \multicolumn{4}{|c|}{ Entire cohort $(n=414)$} & \multicolumn{3}{|c|}{ PSM cohort $(n=112)$} \\
\hline $\begin{array}{l}\text { All patients } \\
(n=414)\end{array}$ & $\begin{array}{c}\text { No statin use } \\
(n=333)\end{array}$ & $\begin{array}{c}\text { Statin use } \\
(\mathrm{n}=81)\end{array}$ & P-value & $\begin{array}{l}\text { No statin use } \\
(n=56)\end{array}$ & $\begin{array}{c}\text { Statin use } \\
(n=56)\end{array}$ & P-value \\
\hline $77 \pm 11$ & $77 \pm 11$ & $78 \pm 10$ & 0.584 & $76 \pm 10$ & $78 \pm 9$ & 0.298 \\
\hline $198(48)$ & $172(52)$ & $26(32)$ & 0.002 & $22(39)$ & $19(34)$ & 0.421 \\
\hline $23.8 \pm 4.9$ & $23.4 \pm 4.8$ & $25.3 \pm 5.0$ & 0.003 & $24.6 \pm 5.3$ & $24.6 \pm 4.4$ & 0.961 \\
\hline $305(74)$ & $231(69)$ & 74 (91) & $<0.001$ & $48(86)$ & 50 (89) & 0.568 \\
\hline $147(36)$ & 79 (24) & $68(84)$ & $<0.001$ & $15(27)$ & $44(79)$ & $<0.001$ \\
\hline $123(30)$ & 95 (29) & $28(35)$ & 0.270 & $20(36)$ & $20(36)$ & 1.000 \\
\hline $270(65)$ & $219(66)$ & $51(63)$ & 0.869 & $44(79)$ & $34(61)$ & 0.054 \\
\hline $43(10)$ & 37 (11) & $6(7.4)$ & 0.444 & $3(5.4)$ & $6(11)$ & 0.427 \\
\hline $134(32)$ & $103(31)$ & $31(38)$ & 0.258 & $22(39)$ & $22(39)$ & 1.000 \\
\hline & & & 0.693 & & & 0.502 \\
\hline $4(1.0)$ & $3(0.9)$ & $1(1.4)$ & & 0 & $1(1.9)$ & \\
\hline $93(23)$ & $75(23)$ & $18(24)$ & & $9(17)$ & $9(17)$ & \\
\hline $164(41)$ & $130(40)$ & $34(46)$ & & $20(38)$ & $26(48)$ & \\
\hline $135(34)$ & $114(35)$ & 21 (28) & & $23(44)$ & $18(33)$ & \\
\hline $119 \pm 21$ & $119 \pm 21$ & $121 \pm 20$ & 0.552 & $119 \pm 19$ & $123 \pm 20$ & 0.312 \\
\hline $63 \pm 13$ & $63 \pm 13$ & $65 \pm 13$ & 0.257 & $64 \pm 12$ & $64 \pm 13$ & 0.879 \\
\hline $\begin{array}{c}324 \\
(176-586)\end{array}$ & $\begin{array}{c}324 \\
(165-586)\end{array}$ & $\begin{array}{c}332 \\
(207-608)\end{array}$ & 0.436 & $\begin{array}{c}287 \\
(104-597)\end{array}$ & $\begin{array}{c}359 \\
(207-638)\end{array}$ & 0.059 \\
\hline $1.18 \pm 0.79$ & $1.17 \pm 0.79$ & $1.23 \pm 0.81$ & 0.518 & $1.05 \pm 0.44$ & $1.30 \pm 0.88$ & 0.052 \\
\hline $53 \pm 26$ & $54 \pm 27$ & $48 \pm 22$ & 0.087 & $53 \pm 22$ & $47 \pm 23$ & 0.130 \\
\hline $3.6 \pm 0.5$ & $3.6 \pm 0.5$ & $3.7 \pm 0.5$ & 0.027 & $3.8 \pm 0.4$ & $3.7 \pm 0.5$ & 0.142 \\
\hline $140 \pm 4$ & $140 \pm 4$ & $141 \pm 4$ & 0.090 & $141 \pm 3$ & $141 \pm 4$ & 0.980 \\
\hline $11.4 \pm 2.2$ & $11.4 \pm 2.3$ & $11.5 \pm 2.0$ & 0.840 & $11.8 \pm 2.2$ & $11.2 \pm 2.0$ & 0.118 \\
\hline $49 \pm 14$ & $48 \pm 14$ & $52 \pm 14$ & 0.033 & $52 \pm 14$ & $52 \pm 14$ & 0.838 \\
\hline $91 \pm 30$ & $92 \pm 31$ & $87 \pm 26$ & 0.263 & $97 \pm 35$ & $85 \pm 27$ & 0.053 \\
\hline $97 \pm 129$ & $93 \pm 138$ & $115 \pm 78$ & 0.206 & $99 \pm 52$ & $112 \pm 74$ & 0.302 \\
\hline $160 \pm 39$ & $160 \pm 40$ & $160 \pm 32$ & 0.935 & $171 \pm 47$ & $156 \pm 33$ & 0.062 \\
\hline $\begin{array}{c}0.27 \\
(0.10-0.89)\end{array}$ & $\begin{array}{c}0.35 \\
(0.11-0.90)\end{array}$ & $\begin{array}{c}0.31 \\
(0.20-0.69)\end{array}$ & 0.817 & $\begin{array}{c}0.40 \\
(0.11-1.09)\end{array}$ & $\begin{array}{c}0.23 \\
(0.08-0.64)\end{array}$ & 0.780 \\
\hline $74 \pm 17$ & $74 \pm 18$ & $73 \pm 16$ & 0.668 & $75 \pm 18$ & $71 \pm 15$ & 0.286 \\
\hline $19(4.6)$ & $14(4.2)$ & $5(6.2)$ & 0.668 & $5(8.9)$ & $5(8.9)$ & 1.000 \\
\hline $11 \pm 3$ & $11 \pm 3$ & $11 \pm 3$ & 0.327 & $11 \pm 3$ & $10 \pm 2$ & 0.428 \\
\hline $11 \pm 2$ & $11 \pm 2$ & $11 \pm 2$ & 0.622 & $11 \pm 2$ & $10 \pm 1$ & 0.326 \\
\hline $46 \pm 7$ & $46 \pm 7$ & $46 \pm 6$ & 0.552 & $46 \pm 8$ & $46 \pm 6$ & 0.809 \\
\hline $60 \pm 8$ & $60 \pm 9$ & $60 \pm 9$ & 0.894 & $60 \pm 8$ & $61 \pm 8$ & 0.851 \\
\hline $45 \pm 10$ & $46 \pm 7$ & $46 \pm 6$ & 0.776 & $46 \pm 10$ & $45 \pm 6$ & 0.667 \\
\hline $100 \pm 35$ & $100 \pm 36$ & $101 \pm 33$ & 0.942 & $103 \pm 35$ & $100 \pm 35$ & 0.694 \\
\hline $80 \pm 34$ & $79 \pm 34$ & $86 \pm 30$ & 0.332 & $76 \pm 36$ & $85 \pm 28$ & 0.367 \\
\hline $1.29 \pm 0.83$ & $1.31 \pm 0.79$ & $1.21 \pm 1.03$ & 0.608 & $1.43 \pm 0.97$ & $1.26 \pm 1.15$ & 0.634 \\
\hline $194 \pm 69$ & $193 \pm 69$ & $196 \pm 71$ & 0.771 & $197 \pm 64$ & $199 \pm 65$ & 0.942 \\
\hline $18.6 \pm 9.2$ & $18.4 \pm 9.1$ & $19.5 \pm 9.9$ & 0.501 & $20.5 \pm 9.5$ & $18.3 \pm 7.5$ & 0.341 \\
\hline $37 \pm 13$ & $37 \pm 13$ & $36 \pm 12$ & 0.794 & $35 \pm 11$ & $38 \pm 12$ & 0.181 \\
\hline 155 (37) & $120(36)$ & $35(43)$ & 0.232 & $28(50)$ & $26(46)$ & 0.705 \\
\hline $227(55)$ & $174(52)$ & $53(65)$ & 0.033 & $34(61)$ & $34(61)$ & 1.000 \\
\hline $88(21)$ & 76 (23) & $12(15)$ & 0.114 & $18(32)$ & $9(16)$ & 0.047 \\
\hline $206(50)$ & $164(49)$ & $42(52)$ & 0.674 & $32(57)$ & $31(55)$ & 0.849 \\
\hline 49 (12) & $37(11)$ & $12(15)$ & 0.335 & $8(14)$ & $9(16)$ & 0.792 \\
\hline $193(47)$ & $154(46)$ & $39(48)$ & 0.758 & $34(61)$ & $24(43)$ & 0.059 \\
\hline
\end{tabular}

Age (years)

Male

BMI $\left(\mathrm{kg} / \mathrm{m}^{2}\right)$

Hypertension

Dyslipidemia

Diabetes mellitus

Atrial fibrillation

Current smoker

History of hospitalization for $\mathrm{HF}$

NYHA functional class $(n=396)$

I
II
III

$\mathrm{SBP}(\mathrm{mmHg})$

$\mathrm{DBP}(\mathrm{mmHg})$

BNP $(\mathrm{pg} / \mathrm{mL})$

Creatinine $(\mathrm{mg} / \mathrm{dL})$

eGFR $\left(\mathrm{mL} / \mathrm{min} / 1.73 \mathrm{~m}^{2}\right)$

Albumin (g/dL)

Serum sodium ( $\mathrm{mEq} / \mathrm{L}$ )

Hemoglobin $(\mathrm{g} / \mathrm{dL})$

HDL-C (mg/mL)

LDL-C $(\mathrm{mg} / \mathrm{mL})$

Triglycerides $(\mathrm{mg} / \mathrm{mL})$

Total cholesterol $(\mathrm{mg} / \mathrm{mL})$

CRP (mg/dL)

ECG variables

Heart rate (beats/min)

CLBBB

Echocardiographic variables

Septal wall thickness $(\mathrm{mm})$

LV posterior wall thickness $(\mathrm{mm})$

Diastolic LV diameter ( $\mathrm{mm}$ )

LVEF (\%)

LAD (mm)

E peak $(\mathrm{cm} / \mathrm{s})$

A peak $(\mathrm{cm} / \mathrm{s})$

E/A

E-wave deceleration time (ms)

E/e'

TRPG ( $\mathrm{mmHg}$ )

Medications at baseline

$\beta$-blocker

ACEI or ARB

Aldosterone antagonist

Diuretic

Digoxin

Anticoagulant

Data given as mean \pm SD, median (IQR) or $n(\%)$. ACEI, angiotensin-converting enzyme inhibitor; ARB, angiotensin receptor blocker; BMI, body mass index; BNP, B-type natriuretic peptide; CLBBB, complete left bundle branch block; CRP, C-reactive protein; DBP, diastolic blood pressure; ECG, electrocardiogram; eGFR, estimated glomerular filtration rate; HDL-C, high-density lipoprotein cholesterol; LAD, left atrium diameter; LDL-C, low-density lipoprotein cholesterol; LV, left ventricular; LVEF, left ventricular ejection fraction; NYHA, New York Heart Association; PSM, propensity score-matched; SBP, systolic blood pressure; TRPG, tricuspid regurgitation peak gradient. 

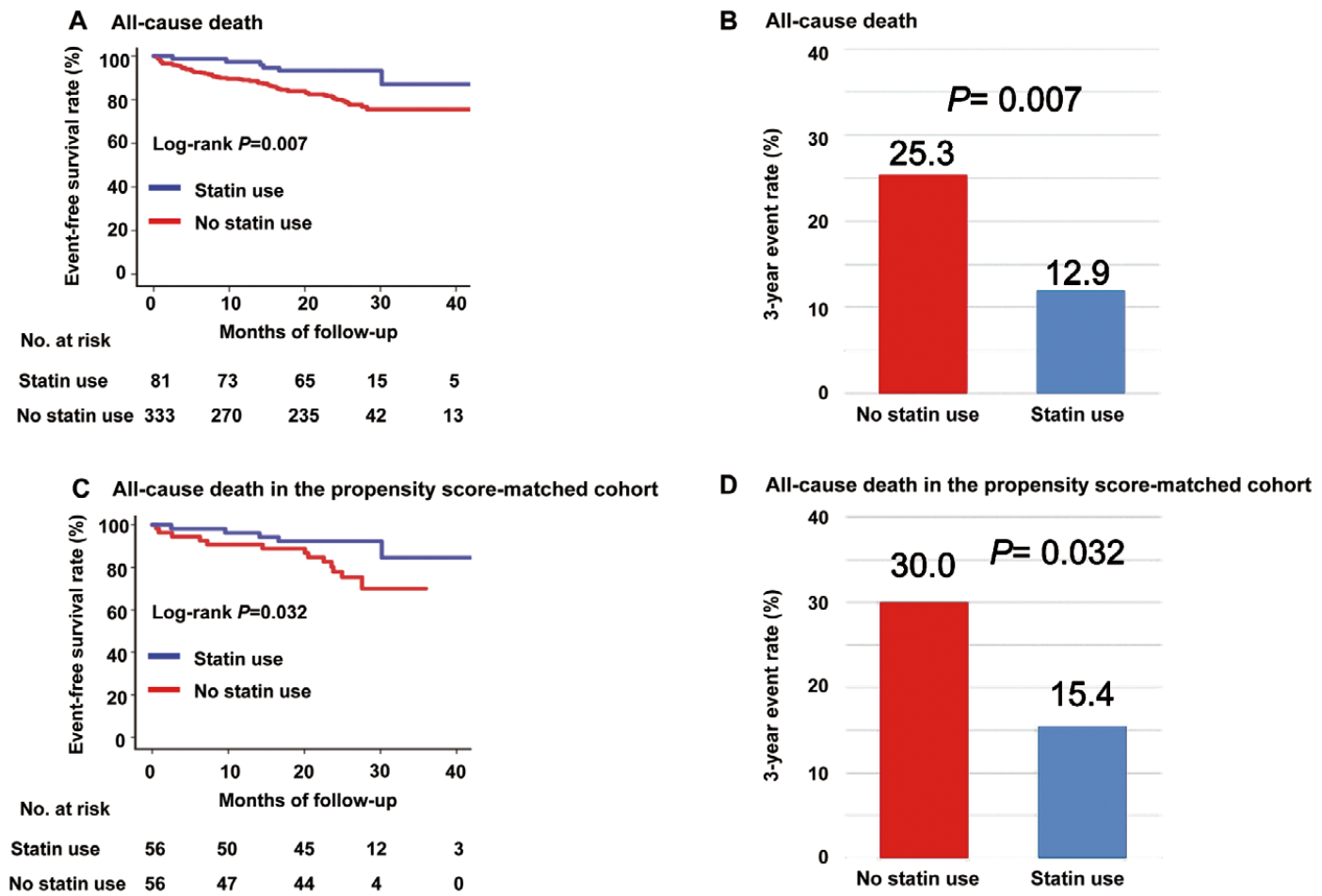

Figure 2. Kaplan-Meier all-cause death $(\mathbf{A}, \mathbf{C})$ event-free survival rate and $(\mathbf{B}, \mathbf{D})$ 3-year event rate in the $(\mathbf{A}, \mathbf{B})$ entire and $(\mathbf{C}, \mathbf{D})$ propensity score-matched cohorts according to statin use.

frequency or percentage. They were compared using the chi-squared test. Cumulative event-free survival was estimated using the Kaplan-Meier method and compared using the log-rank test. Univariable Cox proportional hazards regression models were used to calculate hazard ratios (HR) and 95\% CI for each endpoint. Multivariable Cox regression was performed using covariates that were significantly associated with each endpoint on univariable analysis. Stepwise selection with $\mathrm{P}<0.1$ for backward elimination was used to select the best predictive model. For subgroup analyses of statin use, a Cox proportional hazards model was used to calculate the HR for statin use and P-values for the interaction between statin use and selected baseline variables. We used median B-type natriuretic peptide (BNP; $324 \mathrm{pg} / \mathrm{mL}$ ) as the cut-off for creating a binary explanatory variable. In addition, to reduce the effect of treatment selection bias and possible confounders, we performed adjustment for significant differences in patient baseline characteristics using propensity score matching. The propensity score adjusted for baseline covariates that were significantly different between the 2 groups: gender; prevalence of hypertension; body mass index (BMI); albumin level, and high-density lipoprotein cholesterol (HDL-C) level; and use of ACEI or ARB. Each patient treated with a statin was matched to 1 patient not treated with a statin using nearest-neighbor matching using a caliper width of 0.01 without replacement. All statistical tests were 2-sided and $\mathrm{P}<0.05$ was regarded as statistically significant. Statistical analysis was performed using SPSS version 24.0 (IBM, Armonk, NY, USA).

\section{Results}

Baseline Clinical Characteristics

After excluding 121 patients with a history of MI $(n=66)$, CABG $(n=10)$, or PCI $(n=45)$ from 535 HFpEF patients, 414 patients met the inclusion criteria. All 414 patients were included in the outcome analysis (Figure 1). Mean LVEF was $60 \%$. We divided the patients into 2 groups according to statin use at admission: the statin group $(n=81)$ and the no statin group $(n=333)$. Table 1 compares the baseline clinical characteristics of the 2 groups. Patients in the statin group were less likely to be male (32\% vs. $52 \%$; $\mathrm{P}=0.002)$. They had higher BMI $\left(25.3 \pm 5.0 \mathrm{~kg} / \mathrm{m}^{2} \mathrm{vs}\right.$. $\left.23.4 \pm 4.8 \mathrm{~kg} / \mathrm{m}^{2} ; \mathrm{P}=0.003\right)$ and albumin $(3.7 \pm 0.5 \mathrm{~g} / \mathrm{dL}$ vs. $3.6 \pm 0.5 \mathrm{~g} / \mathrm{dL} ; \mathrm{P}=0.027)$ and a higher prevalence of hypertension $(91 \%$ vs. $69 \% ; \mathrm{P}<0.001)$. The statin group used ACEI or ARB more frequently than the no statin group $(65 \%$ vs. $52 \%$; $\mathrm{P}=0.033)$. As expected, patients taking statins had a higher prevalence of dyslipidemia ( $84 \%$ vs. $24 \% ; \mathrm{P}<0.001)$ and higher HDL-C $(52 \pm 14 \mathrm{mg} / \mathrm{mL}$ vs. $48 \pm 14 \mathrm{mg} / \mathrm{mL} ; \mathrm{P}=0.039)$ than the no statin group. There were no significant differences in BNP or low-density lipoprotein cholesterol (LDL-C), LV systolic function, E/A ratio, or left atrial size.

\section{Hospitalization for Acute HF}

Duration of hospitalization was similar between the statin group (median, 15 days; IQR, 11-23 days) and the no statin group (median, 15 days; IQR, 12-21 days). The statin and no statin groups had similar rates of i.v. treatment $(86 \%$ vs. $89 \% ; \mathrm{P}=0.534)$ and mechanical ventilation $(19 \%$ 
Table 2. Risk Factors for All-Cause Death in HFpEF Without CAD

\begin{tabular}{|c|c|c|c|c|c|c|}
\hline & \multicolumn{3}{|c|}{ Univariable analysis } & \multicolumn{3}{|c|}{ Multivariable analysis } \\
\hline & HR & $95 \% \mathrm{Cl}$ & P-value & HR & $95 \% \mathrm{Cl}$ & P-value \\
\hline Age (per 10-year increment) & 1.59 & $1.21-2.08$ & 0.001 & 1.47 & $1.01-2.15$ & 0.046 \\
\hline Male & 1.17 & $0.74-1.89$ & 0.505 & & & \\
\hline BMI (per 1-kg/m² increment) & 0.90 & $0.85-0.96$ & 0.001 & & Not selected & \\
\hline Hypertension & 0.76 & $0.46-1.27$ & 0.302 & & & \\
\hline Dyslipidemia & 0.47 & $0.28-0.82$ & 0.008 & & VIF & \\
\hline Diabetes mellitus & 0.84 & $0.50-1.42$ & 0.512 & & & \\
\hline Atrial fibrillation & 1.13 & $0.68-1.91$ & 0.637 & & & \\
\hline Current smoker & 0.64 & $0.35-1.18$ & 0.156 & & & \\
\hline History of hospitalization for HF & 1.61 & $0.99-2.62$ & 0.053 & & & \\
\hline NYHA class $\geq$ III & 2.72 & $1.24-5.95$ & 0.012 & & Not selected & \\
\hline SBP (per 10-mmHg increment) & 0.91 & $0.81-1.03$ & 0.150 & & & \\
\hline DBP (per 10-mmHg increment) & 0.88 & $0.73-1.07$ & 0.195 & & & \\
\hline Log (BNP) (per 1-pg/mL increment) & 2.33 & $1.27-4.26$ & 0.006 & & Not selected & \\
\hline eGFR (per $1-\mathrm{mL} / \mathrm{min} / 1.73 \mathrm{~m}^{2}$ decrement) & 1.01 & $1.01-1.02$ & 0.006 & & Not selected & \\
\hline Albumin (per 1-g/dL decrement) & 4.67 & $2.86-4.67$ & $<0.001$ & 7.75 & $3.82-15.63$ & $<0.001$ \\
\hline Serum sodium (per 1-mEq/L decrement) & 1.07 & $1.02-1.12$ & 0.004 & & Not selected & \\
\hline Hemoglobin (per 1-g/dL decrement) & 1.24 & $1.12-1.39$ & $<0.001$ & & Not selected & \\
\hline HDL-C (per 1-mg/mL increment) & 0.98 & $0.96-1.00$ & 0.053 & & & \\
\hline LDL-C (per 1-mg/mL increment) & 0.99 & $0.99-1.00$ & 0.170 & & & \\
\hline Triglycerides (per $1-\mathrm{mg} / \mathrm{mL}$ increment) & 0.99 & $0.99-1.00$ & 0.301 & & & \\
\hline Total cholesterol (per 1-mg/mL increment) & 0.99 & $0.99-1.00$ & 0.171 & & & \\
\hline Log (CRP) (per 1-mg/dL increment) & 1.45 & $1.05-2.07$ & 0.023 & & Not selected & \\
\hline \multicolumn{7}{|l|}{ ECG parameters } \\
\hline Heart rate (per 10-beats/min increment) & 0.96 & $0.89-1.04$ & 0.335 & & & \\
\hline Presence of CLBBB & 0.89 & $0.44-1.80$ & 0.750 & & & \\
\hline \multicolumn{7}{|l|}{ Echocardiographic variables } \\
\hline Septal wall thickness (per 1-mm increment) & 0.99 & $0.90-1.10$ & 0.881 & & & \\
\hline LV posterior wall thickness (per 1-mm increment) & 0.95 & $0.84-1.08$ & 0.441 & & & \\
\hline Diastolic LV diameter (per 1-mm increment) & 1.02 & $0.98-1.05$ & 0.416 & & & \\
\hline LVEF (per $10 \%$ increment) & 1.34 & $0.99-1.81$ & 0.053 & & & \\
\hline LAD (per 5-mm increment) & 1.04 & $0.93-1.18$ & 0.488 & & & \\
\hline E peak (per $1-\mathrm{cm} / \mathrm{s}$ increment) & 1.00 & $0.99-1.01$ & 0.999 & & & \\
\hline A peak (per 1-cm/s increment) & 0.99 & $0.98-1.00$ & 0.160 & & & \\
\hline E-wave deceleration time (per 10-ms increment) & 1.00 & $0.96-1.04$ & 0.990 & & & \\
\hline E/e' (per unit increment) & 1.01 & $0.98-1.04$ & 0.629 & & & \\
\hline TRPG (per 5-mmHg increment) & 1.13 & $1.04-1.23$ & 0.005 & 1.11 & $1.01-1.24$ & 0.041 \\
\hline \multicolumn{7}{|l|}{ Medication at baseline } \\
\hline$\beta$-blocker & 1.53 & $0.96-2.44$ & 0.075 & & & \\
\hline ACEI or ARB & 0.95 & $0.60-1.50$ & 0.820 & & & \\
\hline Aldosterone antagonist & 2.80 & $1.75-4.48$ & $<0.001$ & 2.67 & $1.39-5.19$ & 0.003 \\
\hline Diuretic & 2.50 & $1.51-4.12$ & $<0.001$ & 1.88 & $0.89-3.97$ & 0.098 \\
\hline Digoxin & 0.80 & $0.37-1.74$ & 0.572 & & & \\
\hline Anticoagulant & 1.34 & $0.84-2.12$ & 0.219 & & & \\
\hline Statin & 0.34 & $0.15-0.78$ & 0.011 & 0.33 & $0.11-0.97$ & 0.045 \\
\hline
\end{tabular}

CAD, coronary artery disease; HFpEF, heart failure with preserved ejection fraction; HR, hazard ratio; VIF, variance inflation factor. Other abbreviations as in Table 1.

vs. $18 \% ; \mathrm{P}=0.916)$. During hospitalization, 6 deaths occurred in the no statin group, consisting of 1 cardiac and 5 non-cardiac deaths. In contrast, no patients in the statin group died $(\mathrm{P}=0.224)$.

\section{Primary Endpoint: All-Cause Death}

Table S1 lists the primary and secondary endpoints. During a median follow-up period of 25 months (IQR, 18-28 months), 71 patients (17\%) died. The statin group had a lower incidence of all-cause death than the no statin group $(\mathrm{P}=0.007$; Figure 2A). The estimated 3-year rate for the primary endpoint was lower in the statin group than in the no statin group $(12.9 \%$ vs. $25.3 \%$; $P=0.007$; Figure 2B). Table 2 shows univariable and multivariable Cox regression analyses of risk factors for all-cause death. In a stepwise multivariable Cox model that adjusted for factors that 

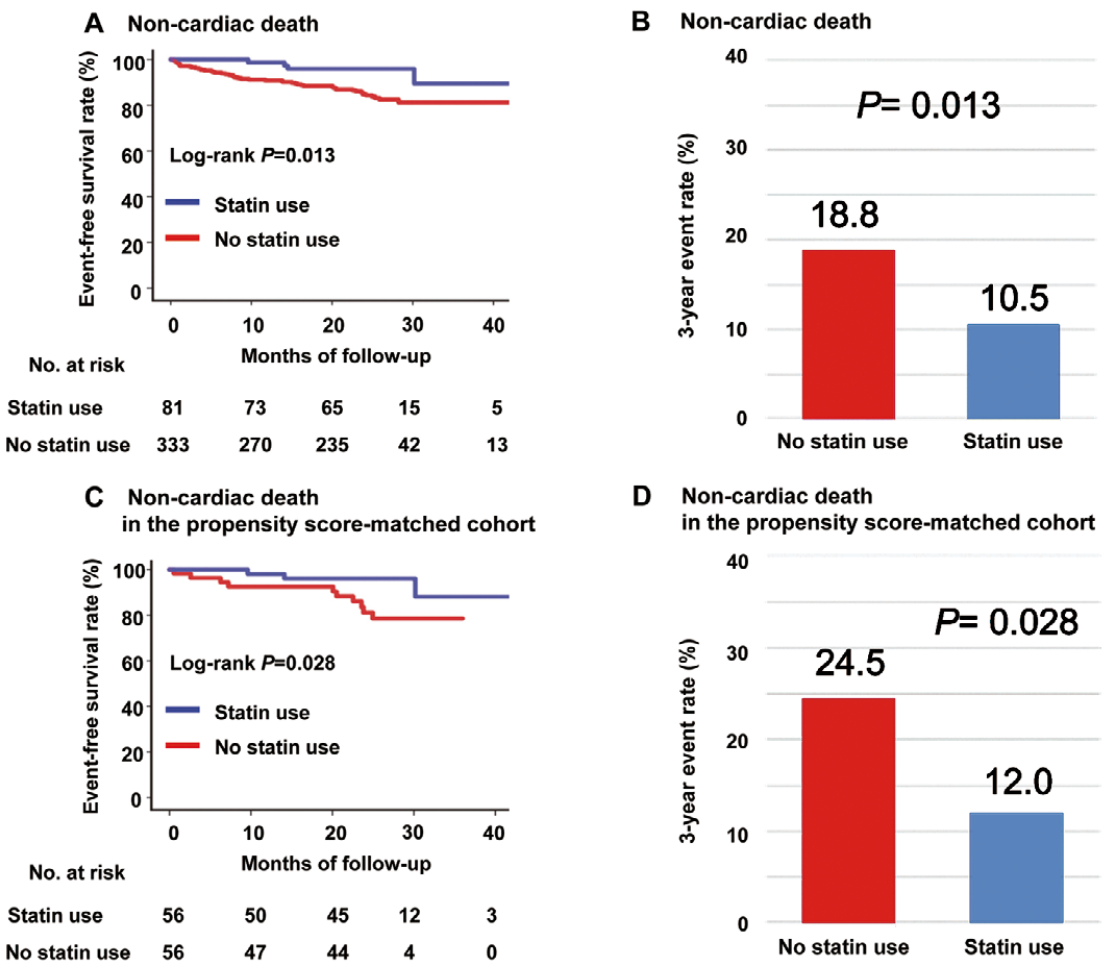

Figure 3. Kaplan-Meier non-cardiac death $(\mathbf{A}, \mathbf{C})$ event-free survival rate and $(\mathbf{B}, \mathbf{D})$ 3-year event rate in the $(\mathbf{A}, \mathbf{B})$ entire and $(\mathbf{C}, \mathbf{D})$ propensity score-matched cohorts according to statin use.

were significant on univariable analysis, statin use was significantly associated with future mortality reduction (HR, 0.33; 95\% CI: 0.11-0.97; $\mathrm{P}=0.045$ ). A propensity score-matched cohort consisting of 56 patients with and without statin use was constructed (Table 1). In this model that matched for gender; BMI; history of hypertension; levels of albumin and HDL-C; and ACEI or ARB use, all-cause death occurred less frequently in the statin group than in the no statin group $(8.9 \%$ vs. $23 \% ; \mathrm{P}=0.040$, Table S1; $\mathrm{P}=0.032$, Figure 2C). The estimated 3-year rate for the primary endpoint was also lower in the statin group than in the no statin group on propensity score matching ( $15.4 \%$ vs. $30 \%$; $\mathrm{P}=0.032$; Figure 2D). On multivariable Cox proportional hazard modeling, statin use was also significantly associated with future mortality reduction (HR, 0.21; 95\% CI: 0.06-0.72; P=0.014; Table S2).

\section{Principal Secondary Endpoints: Non-Cardiac Death and Cardiac Death}

During the follow-up period, non-cardiac death occurred in 53 patients $(13 \%)$. Cardiac death occurred in 18 patients (4.3\%): 2 patients $(0.5 \%)$ died suddenly, and $16(3.9 \%)$ had $\mathrm{HF}$ death. Fewer non-cardiac deaths occurred in the statin group $(\mathrm{P}=0.018$, Table $\mathbf{S 1} ; \mathrm{P}=0.013$, Figure 3A,B $)$. These differences remained after propensity score matching (Figure 3C,D). There were no significant differences, however, in the incidence of cardiac death by statin use (Figure 4A,B). In the propensity score-matched cohort, there were no significant differences in the incidence of cardiac death by statin use (Table S1; Figure 4C,D).

\section{Additional Secondary Endpoint: Rehospitalization for HF}

Rehospitalization for HF occurred in 91 patients $(22 \%)$. There were no significantly differences in the incidence $(\mathrm{P}=0.255$, Table $\mathbf{S 1} ; \mathrm{P}=0.186$, Figure 5A) or estimated 3 -year event rate $(P=0.202$, Figure 5B $)$ of this endpoint between the 2 groups. After propensity score matching, however, the statin group had a lower incidence $(\mathrm{P}=0.001$, Table S1; $\mathrm{P}<0.001$, Figure 5C) and estimated 3-year rate $(\mathrm{P}<0.001$, Figure 5D) of rehospitalization for $\mathrm{HF}$ than the no statin group.

\section{Primary and Secondary Endpoints After Discharge}

To evaluate the effect of statins after discharge, we constructed a new cohort with 387 patients who could be followed after discharge. They were divided into 2 groups based on whether statins were prescribed at discharge: the statin use group $(n=97)$ and the no statin group $(n=290)$. Statin therapy had a beneficial effect on all-cause death $(\mathrm{P}=0.023)$, in particular non-cardiac death $(\mathrm{P}=0.015)$, but not on cardiac death $(\mathrm{P}=0.669$; Figure $\mathrm{S1})$.

\section{Subgroup Analysis}

Figure 6 shows the results of subgroup analyses according to clinically relevant factors in the entire cohort. There were no significant interactions between stain use and other factors such as gender, age, and BNP and LDL-C levels.

\section{Discussion}

In the JASPER study, prescription of statins at admission was associated with a substantial mortality reduction in 


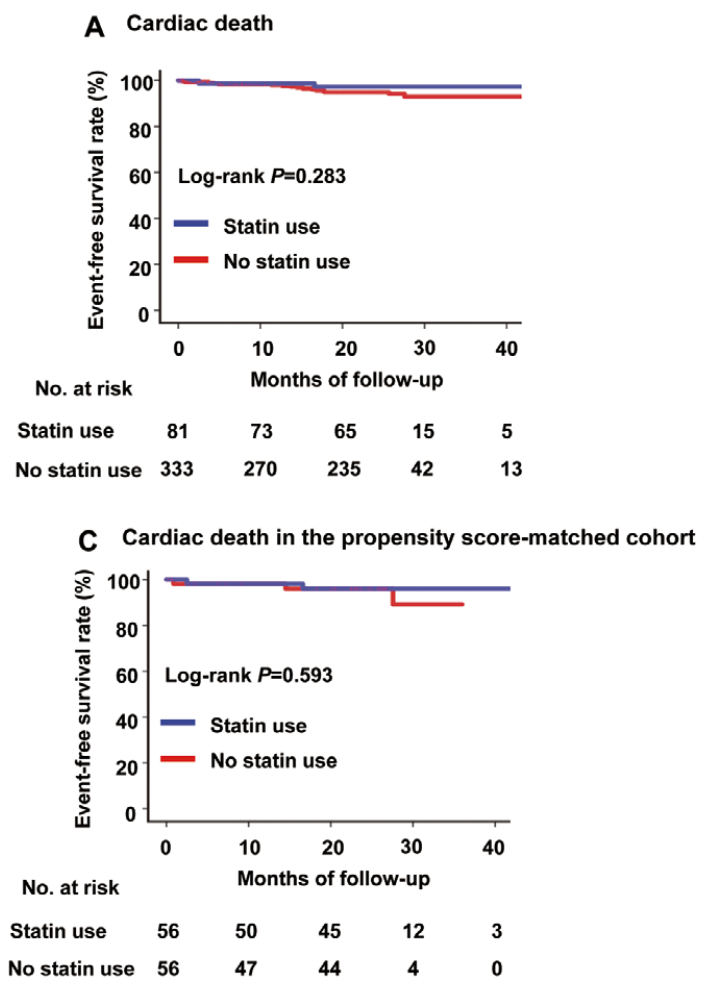

B Cardiac death

40

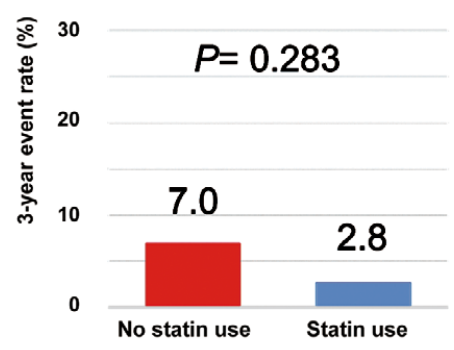

D Cardiac death in the propensity score-matched cohort

40

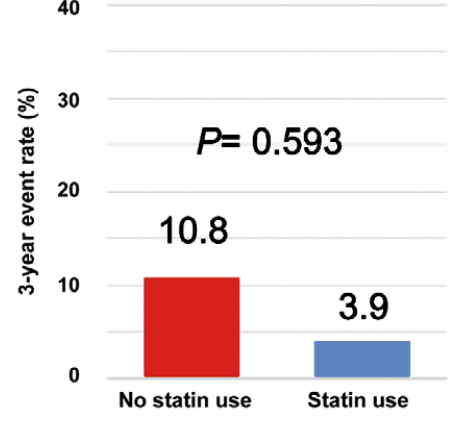

Figure 4. Kaplan-Meier cardiac death $(\mathbf{A}, \mathbf{C})$ event-free survival rate and $(\mathbf{B}, \mathbf{D}) 3$-year event rate in the $(\mathbf{A}, \mathbf{B})$ entire and $(\mathbf{C}, \mathbf{D})$ propensity score-matched cohorts according to statin use.

HFpEF patients without CAD during a median follow-up of 25 months. After propensity score matching, the benefit of statin use was confirmed, and, on multivariable Cox modeling, statin prescription at admission was associated with a $79 \%$ reduction in mortality risk. Decreased mortality was not associated with gender, age, or BNP and LDL-C. To the best of our knowledge, this is the first nationwide study analyzing a cohort of hospitalized HFpEF patients without CAD that has demonstrated the beneficial effects of statins.

\section{Prognostic Effect of Statins in HFpEF}

Some previous studies have shown that statins had a beneficial effect in patients with HFpEF. Preliminary results from Fukuta et al showed that statin use was associated with lower mortality in $\mathrm{HF}$ patients with $\mathrm{EF} \geq 50 \%$ (adjusted HR, 0.20; 95\% CI: $0.06-0.62 ; \mathrm{P}=0.005) .{ }^{11}$ In a recent observational study of 9,140 Swedish patients with $\mathrm{HFpEF}$, statin use was associated with reduced all-cause mortality, cardiovascular mortality, and combined all-cause mortality or cardiovascular hospitalization. ${ }^{\mathbf{1 6}}$ In addition, the Chronic Heart Failure Analysis and Registry in the Tohoku District-2 (CHART-2) study, a multicenter prospective observational study of cardiovascular disease in Japan, showed that statin use was associated with decreased mortality in patients with $\mathrm{HFpEF}$, which was mainly attributable to reductions in sudden and noncardiovascular death. ${ }^{17}$ According to a meta-analysis of 4 studies with 5,526 propensity score-matched patients, statin therapy was associated with reduced mortality (OR,
0.690; 95\% CI: $0.493-0.965 ; \mathrm{P}=0.030) .{ }^{18}$ All of these studies, however, included patients with and without CAD.

\section{Prognostic Effect of Statin in HFpEF Without CAD}

The benefits of statins in patients with CAD are already known. ${ }^{19-23}$ Statin therapy has been reported to reduce acute coronary events, possibly through plaque stabilization, improvement of endothelial and platelet function, and reduction of neutrophil infiltration..$^{38}$ Meanwhile, a substantial number of patients with $\mathrm{HF}$ and sudden death have been documented to have ACS precipitated by plaque rupture on autopsy. ${ }^{39}$ Thus, the efficacy of statin therapy in HF patients with CAD could be primarily related to plaque stabilization and prevention of anti-thrombotic events. The CHART-2 study therefore showed that statin use reduced the risk for sudden death in HFpEF patients, including those with CAD. ${ }^{17}$

The effects of statins in HF patients without CAD, however, remain unknown. A few small randomized trials limited to HF patients with systolic dysfunction showed that statin use had no significant effect on mortality and hospitalization in patients without CAD. ${ }^{\mathbf{4 0 - 4 3}}$ In an observational study on HFpEF from the Swedish Heart Failure Registry, there was a strong interaction between the effect of statin use and presence of CAD (interaction $\mathrm{P}=0.001) .{ }^{44}$ That study showed that statin use had a beneficial effect on mortality in HFpEF patients with CAD (HR, 0.76; 95\% CI: $0.70-0.82 ; \mathrm{P}<0.001)$, but not in those without CAD (HR, 0.95; 95\% CI: 0.85-1.07; $\mathrm{P}=0.43) .{ }^{44}$ In contrast, subgroup analyses in the aforementioned Swedish and 


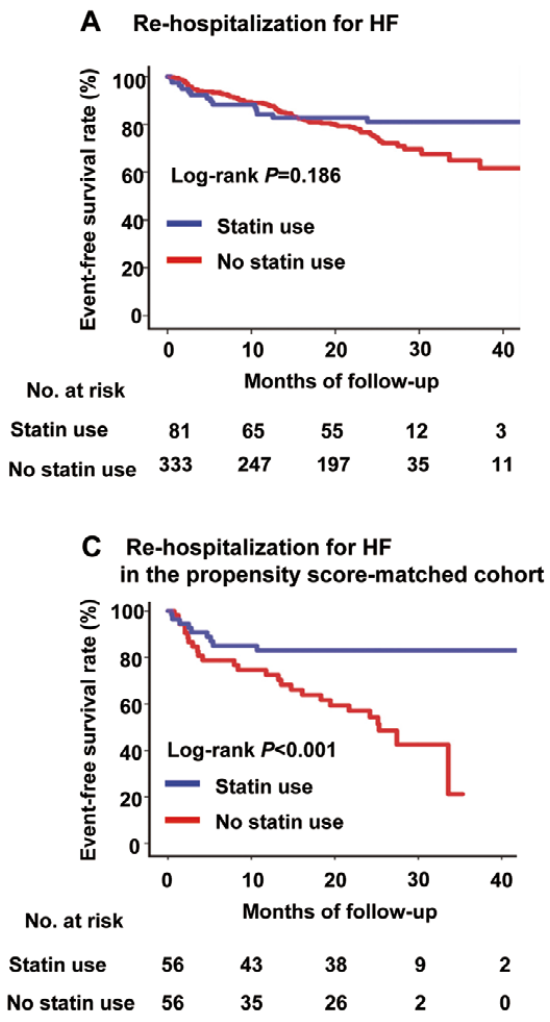

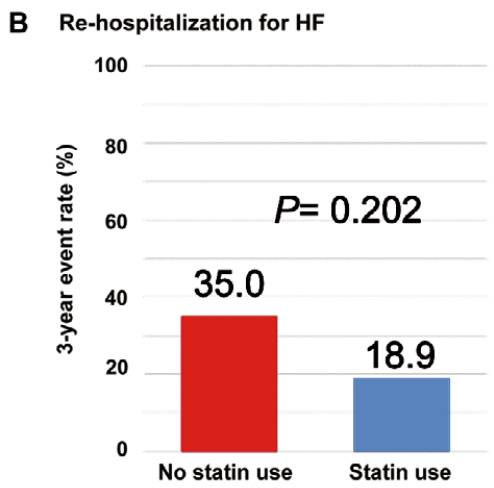

De-hospitalization for HF
in the propensity score-matched cohort

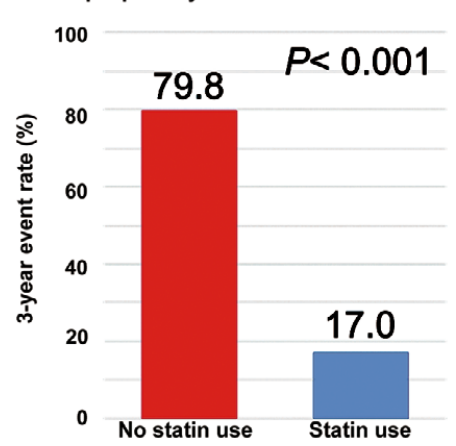

Figure 5. Kaplan-Meier re-hospitalization for heart failure $(\mathrm{HF})(\mathbf{A}, \mathbf{C})$ event-free survival rate and (B,D) 3-year event rate in the $(\mathbf{A}, \mathbf{B})$ entire and $(\mathbf{C}, \mathbf{D})$ propensity score-matched cohorts according to statin use.

Japanese studies showed that statin use was associated with reduced mortality in $\mathrm{HFpEF}$ patients without CAD. ${ }^{16,17}$ Nevertheless, these studies lacked detailed analyses focusing on HFpEF patients without CAD. Thus, we conducted the present study to assess the effect of statins in HFpEF patients without CAD.

We divided HFpEF patients without CAD into 2 groups by statin use. On survival curve analysis, the statin group had a significantly lower incidence of death, especially non-cardiac death, and rehospitalization for HF than the no statin group (Figures 2-5). Although the causes of non-cardiac death in the present study were unclear, the CHART-2 study investigated the cause of death in detail. In that study, 206 of 3,124 patients with HFpEF (6.6\%) had non-cardiovascular death during a follow-up period of 3.4 years. ${ }^{17}$ Cancer $(n=75,36 \%)$ was the most common non-cardiac cause of death, followed by infection $(n=67$, $33 \%)$ and renal failure $(n=18,24 \%) .{ }^{17}$ In particular, the incidence of death due to infection was significantly lower $(\mathrm{P}=0.001)$ and cancer-related mortality tended to be lower $(\mathrm{P}=0.078)$ in the statin use group than in the no statin use group. ${ }^{17}$ In addition, in previous studies statin use was associated with reduced cancer-related mortality ${ }^{45}$ and with a small reduction in the rate of kidney function loss in patients with cardiovascular disease. ${ }^{46}$ Thus, statin therapy might reduce mortality from infection, cancer, and renal failure. Furthermore, despite the lack of significant interactions, the subgroup analyses indicated that statin therapy might be reasonable for patients with a history of hospital- ization for HF; atrial fibrillation; use of $\beta$-blocker, ACEI or ARB; reduced estimated glomerular filtration rate; or increased BNP. Thus, statin therapy is presumed to be effective in patients with advanced HFpEF in addition to $\beta$-blocker, ACEI, or ARB therapy. Although further studies are needed, the present results suggest that statin therapy is effective for patients with $\mathrm{HFpEF}$, even if they do not have CAD.

\section{Possible Mechanisms for Benefits of Statins in HFpEF Without CAD}

The mechanisms by which statins benefit HFpEF patients without CAD are still unknown, but there are some hypotheses. First, patients without CAD might benefit from the pleiotropic effects of statin therapy, including regression of LV hypertrophy and fibrosis, ${ }^{\mathbf{2 4 - 2 6}}$ a mild antihypertensive effect, ${ }^{28}$ improved endothelial and autonomic function, ${ }^{27}$ increased arterial distensibility, ${ }^{28,29}$ and LV remodeling. ${ }^{47}$ Of the 107 patients in the present study who underwent 1-year follow-up echocardiography, LV diastolic diameter of the no statin group showed a non-significant increase (from $45.4 \mathrm{~mm}$ to $46.9 \mathrm{~mm}, \mathrm{P}=0.210$ ). In contrast, the statin group had a non-significant decrease (from $44.9 \mathrm{~mm}$ to $44.3 \mathrm{~mm}, \mathrm{P}=0.573$ ), which suggests that statins could affect LV remodeling. There is limited evidence, however, that these pleiotropic effects can translate into improved outcomes in patients with non-ischemic cardiomyopathy. ${ }^{48}$ Second, other potential beneficial actions of statins that are not limited to effects for HF, such as 


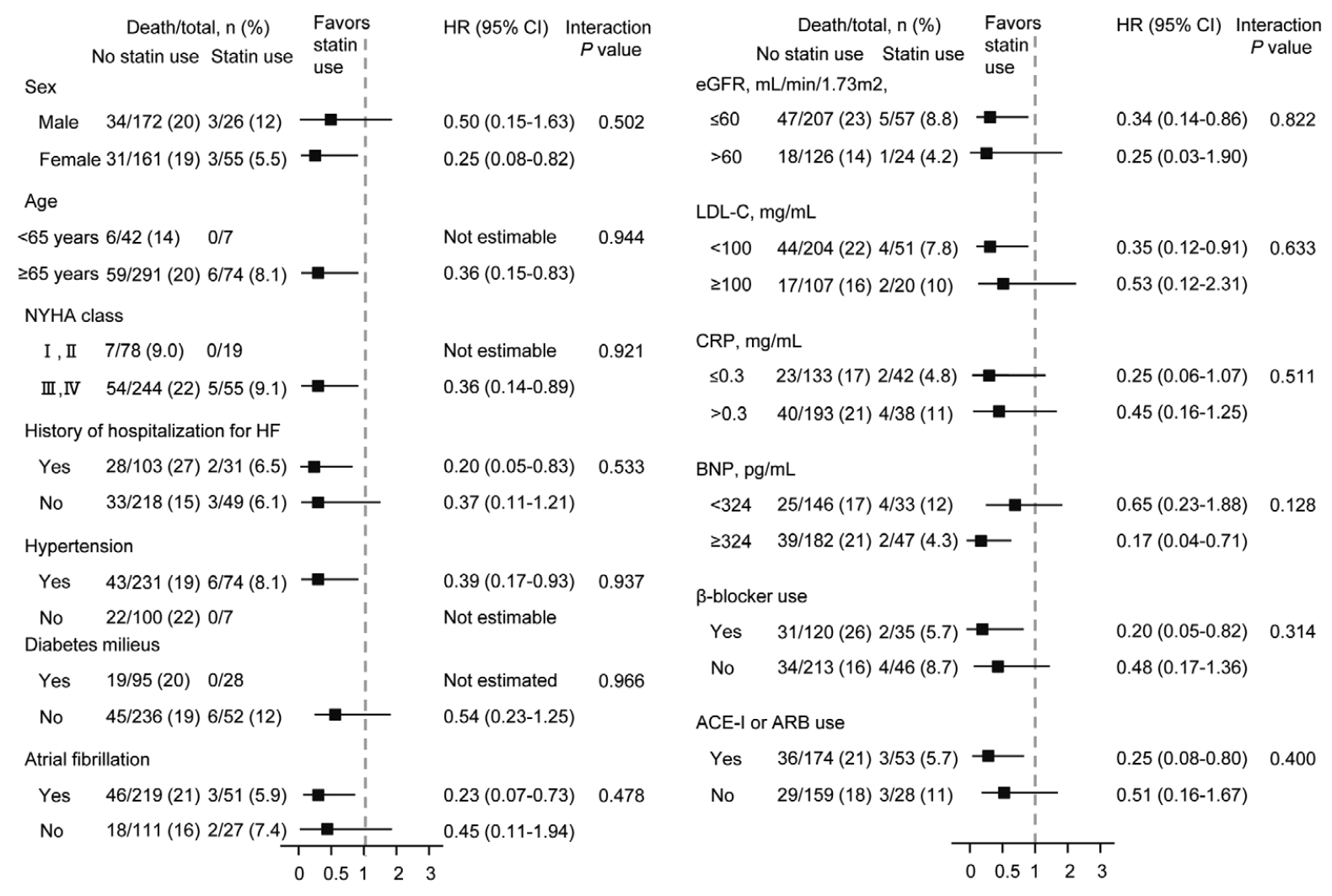

Figure 6. Subgroup analysis of all-cause death by statin use in the entire cohort. ACEI, angiotensin-converting enzyme inhibitor; ARB, angiotensin receptor blocker; BNP, B-type natriuretic peptide; CRP, C-reactive protein; eGFR, estimated glomerular filtration rate; HF, heart failure; HR, hazard ratio; LDL-C, low-density lipoprotein cholesterol; NYHA, New York Heart Association.

anti-inflammatory and antioxidant effects, ${ }^{\mathbf{3 0}, 31}$ might also confer beneficial effects in patients with HFpEF. The CHART-2 study showed that statins were associated with a reduction in the number of infectious deaths among patients HFpEF. ${ }^{17}$ Third, the beneficial effects of statins are likely related to their effects on diabetes ${ }^{49}$ and impaired renal function, ${ }^{\mathbf{5 0}}$ which are common comorbidities in patients with HFpEF. These factors might explain some of the benefit of statins observed in HFpEF patients without CAD.

\section{Study Limitations}

First, the JASPER study is an observational study in which the prescription of statins was not randomized. Even though we performed propensity score matching, the influence of baseline differences in the prevalence of dyslipidemia and unmeasured confounders might not have been completely excluded. Second, lipid profiles at baseline and during treatment were not available for all patients. Furthermore, we do not have complete data on compliance with statin use or subsequent initiation of statin therapy. These factors might have modified the actual clinical effect of statin therapy on mortality. Third, we excluded patients with a history of CAD, but there might be undiagnosed CAD. Only 66 patients $(16 \%)$ underwent evaluation of the coronary arteries on coronary angiography at the beginning of this study, because coronary angiography was based on physician judgment. Moreover, during the follow-up period, some patients might have developed asymptomatic CAD. Future studies should evaluate the coronary arteries in all patient to exclude those with hidden CAD, and assess the effect of statins on endpoints in patients without CAD. Fourth, we could not investigate all causes of death. There was a significant difference in the incidence of non-cardiac death between the statin and no statin groups, but we were not able to assess non-cardiac deaths in detail. Further study should assess this cause of death in detail. Fifth, the number of subjects in this study was relatively smaller than in previous studies. We had well-defined inclusion criteria, however, for hospitalized patients with HF. Therefore, despite the relatively small number of subjects, we believe that the diagnosis of HFpEF was adequately confirmed in the present study. Finally, the results from the stepwise selection process are potentially biased due to overfitting of the derivation data set.

\section{Conclusions}

Statin use has a beneficial effect on mortality in HFpEF patients without CAD. The underlying mechanisms need further investigation. The present findings should be tested in an adequately powered randomized clinical trial.

\section{Acknowledgments}

We are grateful for the contributions of all the investigators, clinical research coordinators, and data managers involved in the JASPER 
study.

JASPER Investigators

Yuji Nagatomo (Department of Cardiology, Sakakibara Heart Institute, Tokyo, Japan); Rika Kawakami (First Department of Internal Medicine, Nara Medical University, Nara, Japan); Akiomi Yoshihisa (Department of Cardiovascular Medicine, Fukushima Medical University, Fukushima, Japan); Yoshiharu Kinugasa (Department of Molecular Medicine and Therapeutics, Faculty of Medicine, Tottori University, Tottori, Japan); Yoshikazu Kishino, Shun Kohsaka, Keiichi Fukuda (Department of Cardiology, Keio University School of Medicine, Tokyo, Japan); Yoshiro Naito, Tohru Masuyama (Cardiovascular Division, Department of Internal Medicine, Hyogo College of Medicine, Hyogo, Japan); Yuji Hashimoto (Department of Cardiology, Kameda Medical Center, Chiba, Japan); Megumi Yamamuro (Department of Cardiovascular Medicine, Faculty of Life Sciences, Graduate School of Medical Science, Kumamoto University, Kumamoto, Japan); Kazuaki Wakami, Nobuyuki Ohte (Department of Cardio-Renal Medicine and Hypertension, Nagoya City University, Japan); Chisato Izumi, Yoshihisa Nakagawa (Department of Cardiology, Tenri Hospital, Tenri, Japan); Ayumi Goda, Hideaki Yoshino (Division of Cardiology, Department of Internal Medicine II, Kyorin University School of Medicine, Tokyo, Japan); Shintaro Kinugawa, Hiroyuki Tsutsui (Department of Cardiovascular Medicine, Hokkaido University Graduate School of Medicine, Sapporo, Japan); Tsuyoshi Ono, Kaoru Sugi (Division of Cardiovascular Medicine, Toho University Ohashi Medical Center, Tokyo, Japan); Kazuo Ogawa, Michihiro Yoshimura (Division of Cardiology, Department of Internal Medicine, The Jikei University School of Medicine, Tokyo, Japan); Yasuhide Asaumi, Yasuo Sugano, Hideaki Kanzaki, Takahiro Ohara, Teruo Noguchi, Kengo Kusano, Toshiaki Shishido, Satoshi Yasuda (Department of Cardiovascular Medicine, National Cerebral and Cardiovascular Center).

Kuniko Sugaya, Yoko Sumita (Department of Cardiovascular Medicine, National Cerebral and Cardiovascular Center, Osaka, Japan).

\section{Disclosures}

The authors declare no conflicts of interest.

\section{References}

1. Go AS, Mozaffarian D, Roger VL, Benjamin EJ, Berry JD, Borden WB, et al. Heart disease and stroke statistics - 2013 update: A report from the American Heart Association. Circulation 2013; 127: e6-e245.

2. Sakata Y, Shimokawa H. Epidemiology of heart failure in Asia. Circ J 2013; 77: 2209-2217.

3. Owan TE, Hodge DO, Herges RM, Jacobsen SJ, Roger VL, Redfield MM. Trends in prevalence and outcome of heart failure with preserved ejection fraction. N Engl J Med 2006; 355: 251 259.

4. Vasan RS, Larson MG, Benjamin EJ, Evans JC, Reiss CK, Levy D. Congestive heart failure in subjects with normal versus reduced left ventricular ejection fraction: Prevalence and mortality in a population-based cohort. J Am Coll Cardiol 1999; 33: $1948-1955$.

5. Tsuchihashi-Makaya M, Hamaguchi S, Kinugawa S, Yokota T, Goto D, Yokoshiki H, et al. Characteristics and outcomes of hospitalized patients with heart failure and reduced vs preserved ejection fraction: Report from the Japanese Cardiac Registry of Heart Failure in Cardiology (JCARE-CARD). Circ J 2009; 73: $1893-1900$.

6. Cleland JG, Tendera M, Adamus J, Freemantle N, Polonski L, Taylor J. The perindopril in elderly people with chronic heart failure (PEP-CHF) study. Eur Heart J 2006; 27: 2338-2345.

7. Yusuf S, Pfeffer MA, Swedberg K, Granger CB, Held P, McMurray JJ, et al. Effects of candesartan in patients with chronic heart failure and preserved left-ventricular ejection fraction: The CHARM-Preserved Trial. Lancet 2003; 362: $777-$ 781.

8. Massie BM, Carson PE, McMurray JJ, Komajda M, McKelvie $\mathrm{R}$, Zile MR, et al. Irbesartan in patients with heart failure and preserved ejection fraction. $N$ Engl J Med 2008; 359: 2456-2467.

9. Pitt B, Pfeffer MA, Assmann SF, Boineau R, Anand IS, Claggett $\mathrm{B}$, et al. Spironolactone for heart failure with preserved ejection fraction. N Engl J Med 2014; 370: 1383-1392.

10. Hori M, Kitabatake A, Tsutsui H, Okamoto H, Shirato K, Nagai R, et al. Rationale and design of a randomized trial to assess the effects of beta-blocker in diastolic heart failure; Japanese Diastolic Heart Failure Study (J-DHF). J Card Fail 2005; 11: $542-547$.

11. Fukuta H, Sane DC, Brucks S, Little WC. Statin therapy may be associated with lower mortality in patients with diastolic heart failure: A preliminary report. Circulation 2005; 112: 357-363.

12. Roik M, Starczewska MH, Huczek Z, Kochanowski J, Opolski G. Statin therapy and mortality among patients hospitalized with heart failure and preserved left ventricular function: A preliminary report. Acta Cardiol 2008; 63: 683-692.

13. Shah R, Wang Y, Foody JM. Effect of statins, angiotensinconverting enzyme inhibitors, and beta blockers on survival in patients $\geq 65$ years of age with heart failure and preserved left ventricular systolic function. Am J Cardiol 2008; 101: 217-222.

14. Ouzounian M, Tu JV, Austin PC, Chong A, Liu PP, Lee DS. Statin therapy and clinical outcomes in heart failure: A propensitymatched analysis. J Card Fail 2009; 15: $241-248$.

15. Kaneko H, Suzuki S, Yajima J, Oikawa Y, Sagara K, Otsuka T, et al. Clinical characteristics and long-term clinical outcomes of Japanese heart failure patients with preserved versus reduced left ventricular ejection fraction: A prospective cohort of Shinken Database 2004-2011. J Cardiol 2013; 62: 102-109.

16. Alehagen U, Benson L, Edner M, Dahlstrom U, Lund LH. Association between use of statins and mortality in patients with heart failure and ejection fraction of $\geq 50$. Circ Heart Fail 2015; 8: $862-870$.

17. Nochioka K, Sakata Y, Miyata S, Miura M, Takada T, Tadaki $\mathrm{S}$, et al. Prognostic impact of statin use in patients with heart failure and preserved ejection fraction. Circ J 2015; 79: 574-582.

18. Fukuta H, Goto T, Wakami K, Ohte N. The effect of statins on mortality in heart failure with preserved ejection fraction: A meta-analysis of propensity score analyses. Int J Cardiol 2016; 214: $301-306$.

19. Randomised trial of cholesterol lowering in 4444 patients with coronary heart disease: The Scandinavian Simvastatin Survival Study (4S). Lancet 1994; 344: 1383-1389.

20. Heart Protection Study Collaboration Group. MRC/BHF Heart Protection Study of cholesterol lowering with simvastatin in 20,536 high-risk individuals: A randomised placebo-controlled trial. Lancet 2002; 360: 7-22.

21. The Long-Term Intervention with Pravastatin in Ischemic Disease (LIPID) Study Group. Prevention of cardiovascular events and death with pravastatin in patients with coronary heart disease and a broad range of initial cholesterol levels. $N$ Engl $J$ Med 1998; 339: 1349-1357.

22. Sacks FM, Pfeffer MA, Moye LA, Rouleau JL, Rutherford JD, Cole TG, et al. The effect of pravastatin on coronary events after myocardial infarction in patients with average cholesterol levels: Cholesterol and Recurrent Events Trial investigators. $N$ Engl J Med 1996; 335: 1001-1009.

23. Levine GN, Keaney JF Jr, Vita JA. Cholesterol reduction in cardiovascular disease: Clinical benefits and possible mechanisms. N Engl J Med 1995; 332: 512-521.

24. Nishikawa H, Miura S, Zhang B, Shimomura H, Arai H, Tsuchiya Y, et al. Statins induce the regression of left ventricular mass in patients with angina. Circ J 2004; 68: 121-125.

25. Patel R, Nagueh SF, Tsybouleva N, Abdellatif M, Lutucuta S, Kopelen HA, et al. Simvastatin induces regression of cardiac hypertrophy and fibrosis and improves cardiac function in a transgenic rabbit model of human hypertrophic cardiomyopathy. Circulation 2001; 104: 317-324.

26. Indolfi C, Di Lorenzo E, Perrino C, Stingone AM, Curcio A, Torella D, et al. Hydroxymethylglutaryl coenzyme A reductase inhibitor simvastatin prevents cardiac hypertrophy induced by pressure overload and inhibits p21ras activation. Circulation 2002; 106: $2118-2124$.

27. Davignon J. Beneficial cardiovascular pleiotropic effects of statins. Circulation 2004; 109: Iii39-Iii43.

28. Ferrier KE, Muhlmann MH, Baguet JP, Cameron JD, Jennings GL, Dart AM, et al. Intensive cholesterol reduction lowers blood pressure and large artery stiffness in isolated systolic hypertension. J Am Coll Cardiol 2002; 39: 1020-1025.

29. Smilde TJ, van den Berkmortel FW, Wollersheim H, van Langen $\mathrm{H}$, Kastelein JJ, Stalenhoef AF. The effect of cholesterol lowering on carotid and femoral artery wall stiffness and thickness in patients with familial hypercholesterolaemia. Eur J Clin Invest 2000; 30: 473-480.

30. Mitchell LB, Powell JL, Gillis AM, Kehl V, Hallstrom AP. Are lipid-lowering drugs also antiarrhythmic drugs?: An analysis of the Antiarrhythmics versus Implantable Defibrillators (AVID) 
trial. J Am Coll Cardiol 2003; 42: 81-87.

31. Vyas AK, Guo H, Moss AJ, Olshansky B, McNitt SA, Hall WJ, et al. Reduction in ventricular tachyarrhythmias with statins in the Multicenter Automatic Defibrillator Implantation Trial (MADIT)-II. J Am Coll Cardiol 2006; 47: 769-773.

32. Zile MR, Brutsaert DL. New concepts in diastolic dysfunction and diastolic heart failure: Part II: Causal mechanisms and treatment. Circulation 2002; 105: 1503-1508.

33. Senni M, Paulus WJ, Gavazzi A, Fraser AG, Diez J, Solomon $\mathrm{SD}$, et al. New strategies for heart failure with preserved ejection fraction: The importance of targeted therapies for heart failure phenotypes. Eur Heart J 2014; 35: 2797-2815.

34. Yancy CW, Jessup M, Bozkurt B, Butler J, Casey DE Jr, Drazner $\mathrm{MH}$, et al. 2013 ACCF/AHA guideline for the management of heart failure: A report of the American College of Cardiology Foundation/American Heart Association Task Force on Practice Guidelines. J Am Coll Cardiol 2013; 62: e147-e239.

35. Nagai T, Yoshikawa T, Saito Y, Takeishi Y, Yamamoto K, Ogawa $\mathrm{H}$, et al. Clinical characteristics, management, and outcomes of Japanese patients hospitalized for heart failure with preserved ejection fraction: A report from the Japanese Heart Failure Syndrome With Preserved Ejection Fraction (JASPER) Registry. Circ J 2018; 82: 1534-1545.

36. Mantel A, Holmqvist M, Andersson DC, Lund LH, Askling J. Association between rheumatoid arthritis and risk of ischemic and nonischemic heart failure. J Am Coll Cardiol 2017; 69: $1275-1285$.

37. Hicks KA, Tcheng JE, Bozkurt B, Chaitman BR, Cutlip DE, Farb A, et al. 2014 ACC/AHA key data elements and definitions for cardiovascular endpoint events in clinical trials: A report of the American College of Cardiology/American Heart Association Task Force on Clinical Data Standards (Writing Committee to Develop Cardiovascular Endpoints Data Standards). Circulation 2015; 132: 302-361.

38. Kayikcioglu M, Can L, Evrengul H, Payzin S, Kultursay H. The effect of statin therapy on ventricular late potentials in acute myocardial infarction. Int J Cardiol 2003; 90: 63-72.

39. Uretsky BF, Thygesen K, Armstrong PW, Cleland JG, Horowitz $\mathrm{JD}$, Massie BM, et al. Acute coronary findings at autopsy in heart failure patients with sudden death: Results from the assessment of treatment with lisinopril and survival (ATLAS) trial. Circulation 2000; 102: 611-616.

40. Wojnicz R, Wilczek K, Nowalany-Kozielska E, SzygulaJurkiewicz B, Nowak J, Polonski L, et al. Usefulness of atorvastatin in patients with heart failure due to inflammatory dilated cardiomyopathy and elevated cholesterol levels. Am J Cardiol 2006; 97: 899-904.

41. Sola S, Mir MQ, Lerakis S, Tandon N, Khan BV. Atorvastatin improves left ventricular systolic function and serum markers of inflammation in nonischemic heart failure. $\mathrm{J}$ Am Coll Cardiol 2006; 47: 332-337.

42. Laufs U, Wassmann S, Schackmann S, Heeschen C, Bohm M, Nickenig G. Beneficial effects of statins in patients with nonischemic heart failure. Z Kardiol 2004; 93: 103-108.

43. Node K, Fujita M, Kitakaze M, Hori M, Liao JK. Short-term statin therapy improves cardiac function and symptoms in patients with idiopathic dilated cardiomyopathy. Circulation 2003; 108: 839-843.

44. Alehagen U, Benson L, Edner M, Dahlstrom U, Lund LH. Association between use of statins and outcomes in heart failure with reduced ejection fraction: Prospective propensity score matched cohort study of 21864 patients in the Swedish Heart Failure Registry. Circ Heart Fail 2015; 8: 252-260.

45. Nielsen SF, Nordestgaard BG, Bojesen SE. Statin use and reduced cancer-related mortality. $N$ Engl J Med 2012; 367: $1792-1802$.

46. Sandhu S, Wiebe N, Fried LF, Tonelli M. Statins for improving renal outcomes: A meta-analysis. J Am Soc Nephrol 2006; 17: 2006-2016.

47. Bauersachs J, Galuppo P, Fraccarollo D, Christ M, Ertl G. Improvement of left ventricular remodeling and function by hydroxymethylglutaryl coenzyme a reductase inhibition with cerivastatin in rats with heart failure after myocardial infarction. Circulation 2001; 104: 982-985.

48. Raina A, Pickering T, Shimbo D. Statin use in heart failure: A cause for concern? Am Heart J 2006; 152: 39-49.

49. Collins R, Armitage J, Parish S, Sleigh P, Peto R. MRC/BHF Heart Protection Study of cholesterol-lowering with simvastatin in 5963 people with diabetes: A randomised placebo-controlled trial. Lancet 2003; 361: 2005-2016.

50. Tonelli M, Moye L, Sacks FM, Kiberd B, Curhan G. Pravastatin for secondary prevention of cardiovascular events in persons with mild chronic renal insufficiency. Ann Intern Med 2003; 138: $98-104$.

\section{Supplementary Files}

\section{Supplementary File 1}

Figure S1. Kaplan-Meier curves for (A) all-cause death, (B) noncardiac death, $(\mathbf{C})$ cardiac death and $(\mathbf{D})$ rehospitalization for heart failure (HF) according to statin use at discharge.

Table S1. Primary and secondary endpoints during follow-up

Table S2. Risk factors for all-cause death in HFpEF without $\mathrm{CAD}$ in the propensity score-matched cohort

Please find supplementary file(s);

http://dx.doi.org/10.1253/circj.CJ-18-0639 